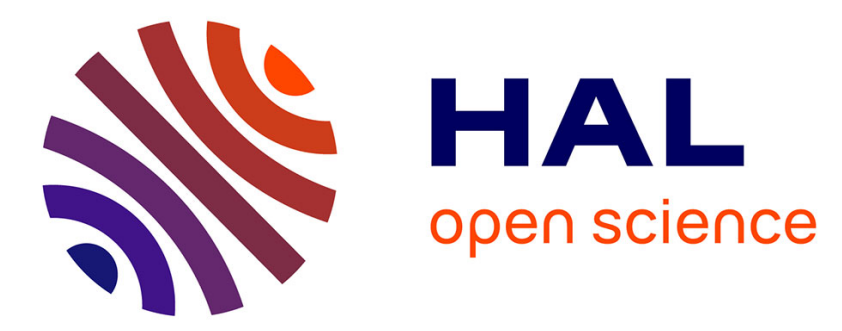

\title{
Tuning of Cascaded Controllers for Robust Grid-Forming Voltage Source Converter
}

T. Qoria, F. Gruson, F. Colas, X. Guillaud, M-S. Debry, T. Prevost

\section{To cite this version:}

T. Qoria, F. Gruson, F. Colas, X. Guillaud, M-S. Debry, et al.. Tuning of Cascaded Controllers for Robust Grid-Forming Voltage Source Converter. 2018 Power Systems Computation Conference (PSCC), Jun 2018, Dublin, Ireland. 10.23919/PSCC.2018.8443018 . hal-02267404

\section{HAL Id: hal-02267404 https://hal.science/hal-02267404}

Submitted on 19 Aug 2019

HAL is a multi-disciplinary open access archive for the deposit and dissemination of scientific research documents, whether they are published or not. The documents may come from teaching and research institutions in France or abroad, or from public or private research centers.
L'archive ouverte pluridisciplinaire HAL, est destinée au dépôt et à la diffusion de documents scientifiques de niveau recherche, publiés ou non, émanant des établissements d'enseignement et de recherche français ou étrangers, des laboratoires publics ou privés. 


\section{Tuning of cascaded controllers for robust grid-forming Voltage Source Converter}

\author{
T. QORIA, F. GRUSON, F. COLAS, X. GUILLAUD \\ Univ. Lille, Centrale Lille, Arts et Métiers Paris Tech, HEI, \\ EA 2697 - L2EP - Laboratoire d'Electrotechnique \\ et d'Electronique de Puissance, F-59000 Lille, France \\ taoufik.qoria@ensam.eu
}

\author{
M-S. DEBRY, T. PREVOST \\ Reseau de Transport d'Electricite (RTE) \\ Versailles, FRANCE
}

\begin{abstract}
From the origin of the grid, energy has been delivered to electrical loads mainly by synchronous machines. All the main rules to manage the grid have been based on the electromechanical behavior of these machines which have been extensively studied for many years. Due to the increase of HVDC link and renewable energy sources as wind turbine and PV, power converters are massively introduced in the grid with a fundamentally different dynamic behavior. Some years ago, they were connected as simple power injector. Then, they were asked to provide some ancillary services to the grid, in the future, grid forming capability will be required. Even if gridforming converters had been extensively studied for microgrids and offshore grids, it has to be adapted to transmission grid where the topology may be largely modified. This paper presents an algorithm for calculating the controller parameters of a gridforming converter which guarantee a stable behavior for many different configurations of the grid.
\end{abstract}

Index Terms-Transmission system, Grid-forming control, Parameters of Controllers, Tuning algorithm, Small-signals analysis.

\section{INTRODUCTION}

The rapid increase in the production of electricity from renewable energies (solar, wind) as well as the interconnection of synchronous or asynchronous zones by high voltage direct current (HVDC) links [1] leads the electric power transmission grid to undergo an unprecedented mutation. Indeed, photovoltaic or wind-based production systems are interfaced to the alternative transmission system through power electronics devices, and HVDC interconnections also use static converters. Then, the penetration rate of power electronics in transmission grid is steadily increasing, which leads to some fundamental modifications in the grid since their physical behavior is fundamentally different from the classical synchronous machine. When the renewable energy started to grow, these sources were considered as "negative load" meaning that the grid had to cope with new kind of loads which were producing more power than consuming. This is the base of grid following mode [2][3] where the converter injects power in the grid and needs a PLL to be synchronized to the grid voltage [4]. By increasing the power electronic converter penetration, a grid supporting capability has been asked for [5], mainly in term of voltage and sometime in term of frequency. The way to connect this kind of converter is still the same: an active and reactive power injector with an added function of voltage or frequency regulation as in classical electrical power sources. The major disadvantage of this mode of connection is the impossibility to operate in islanded mode and stability issues in case of a lower Short Circuit Ratio (SCR) mainly due to the PLL dynamics [6][7]. In the future, it is expected that large geographical areas will be fed at some time of the year only by power converters [8], so a power injector behavior for the converters, as it is now, will not be able to manage this kind of situation. In this case, the VSCs may need to operate autonomously, the power converter will have to generate the voltage waveform. This is the concept of grid forming converter [9].

Due to the physical nature of the converter, it will not control only the voltage RMS value, but also the instantaneous waveform. This control technique has been used in UPS [10] and extensively studied in micro-grid [11]-[13]. But transmission grids have their own specificities compared to the distribution grid which induces specific studies to guarantee the same quality of service as today [14]. Among them, the robustness to various topologies is quite challenging since the transmission grids are subject to various events as loads connection, trip of lines, short circuits, etc.

The high controllability of the power electronic converter may be an advantage but also a drawback since a high dynamic voltage control may deliver a very good voltage quality to the grid around an operating point but also may suffer of a poor robustness when subjected to different situations previously mentioned.

The robustness improvement of the control of these converters is the main point addressed in this paper. This approach has to take into account the specificities of converters connected to transmission grid. Indeed, since the power rating of VSCs in transmission grid can be very high, the switching frequency is rather low to limit the losses, this implies a limitation of the control bandwidth. Furthermore, the converters are connected to the grid thanks to an LCL filter, the sizing of this filter has also to be taken into account. Various types of control algorithms could be considered but to ease the 
implementation in an industrial converter, a classical voltage and current loop has been kept. Two solutions had been proposed in the literature to deal with this issue, the first one is based on the choice of the LCL filter parameters, e.g., as increasing on the capacitor value [18]. The second one consists in acting on the feed-forward disturbances rejection in the inner loops at the control level [15]-[21]. In all these solutions, the system dynamics are not very well controlled. This paper exposes clearly the instability origin due to the interaction between system modes, therefore, time decoupling is not possible due to the bandwidth limitation. The objective of this paper is to take into account the overall dynamics of the system and to find a setting of controllers parameters satisfying a good stability, damping as well as a very high robustness with respect to the various grid topology. The determination of the parameters is done via an algorithm which responds to several imposed constraints. To formalize this problem and check the system stability, small-signal analysis and participation factors tool [22] have been used. The paper is organized as follows. In section II, modeling of a grid-forming control for transmission power systems and recall on classical controllers tuning are presented and tested in two different grid topologies in order to check the classical tuning method limitations. In section III, small-signal analysis for grid-forming converter is discussed in order to understand the instability origin. Finally, the proposed controllers tuning algorithm is presented and tested in section IV to highlight the very good dynamics and robustness obtained with the proposed method. Conclusions are drawn in Section V.

\section{GRID-FORMING CONTROL FOR TRANSMISSION POWER SYSTEM}

Because of their capability to operate in different topologies, grid-forming voltage source converters will be used for future transmission grid (MIGRATE PROJECT [23]). In this article, the studied grid-forming VSC consists of a 2-Levels VSC supplied by a DC bus and connected to the AC side through an LCL filter.

As explained in the introduction, this converter has to cope with various situations which are modeled here by two extreme cases :

- Standalone mode where the converter and its filter is connected only to one load (K1 open in Figure 1).

- Connection to an infinite grid modeled by a Thevenin voltage source and its equivalent impedance (K1 closed in Figure 1). An LCL filter is very often used in grid-feeding converter, so the main difference is not the topology of the converter itself but its control since an instantaneous voltage loop is implemented in grid-forming control whereas grid-feeding is mainly focused on the control of the current or the power. In case of an association of several grid forming converters, a droop control [20] is added to share the active and reactive power between them.

The upper part of Figure 1 shows the general organization of the considered grid-forming control.

\section{A. System Modeling}

Following the notations in Figure 1, the accessible state variables are respectively the VSC current $i_{s}$, the voltage across the filter capacitor $e_{g}$ and the current $i_{g}$ through the transformer inductance $L_{c}$.

To simplify the system study, the VSC is represented by its average model, and the state variables are represented in $d-q$ frame in order to control DC variables as expressed by the dynamic equations below.

$$
\begin{array}{r}
v_{m d}-e_{g d}=\frac{L_{f}}{w_{b}} \dot{i_{s d}}+R_{f} i_{s d}-L_{f} w_{0} i_{s q} \\
v_{m q}-e_{g q}=\frac{L_{f}}{w_{b}} \dot{i_{s q}}+R_{f} i_{s q}+L_{f} w_{0} i_{s d} \\
i_{s d}-i_{g d}=\frac{C_{f}}{w_{b}} \dot{e_{g d}}-C_{f} w_{0} e_{g q} \\
i_{s q}-i_{g q}=\frac{C_{f}}{w_{b}} \dot{e_{g q}}+C_{f} w_{0} e_{g d} \\
e_{g d}-v_{p c c_{d}}=\frac{L_{c}}{w_{b}} \dot{i_{g d}}+R_{c} i_{g d}-L_{c} w_{0} i_{g q} \\
e_{g q}-v_{p c c_{q}}=\frac{L_{c}}{w_{b}} \dot{i_{g q}}+R_{c} i_{g q}+L_{c} w_{0} i_{g d}
\end{array}
$$

The quantities are expressed in (Per-unit) except $w_{b}$ which is the base frequency in $(\mathrm{rad} / \mathrm{s})$.

\section{B. Grid-forming Cascaded-Loops Control}

The grid-forming control consists of three main stages as shown in Figure 1:

- The linearization stage that provides modulation signals.

- The inner control loops : current and voltage control.

- The primary control which is constituted of the active power droop that provides the control angle $\theta_{\text {ref }}$ and the reactive power droop that provides the d-axis reference $e_{g_{d r e f}}$ to the voltage loop.

Using the two-axis theory, the injected instantaneous active and reactive power components, $p_{m e s}$ and $q_{m e s}$, are given by the following equations :

$$
\begin{aligned}
& p_{m e s}=e_{g d} i_{g d}+e_{g q} i_{g q} \\
& q_{m e s}=e_{g d} i_{g q}-e_{g q} i_{g d}
\end{aligned}
$$

To ensure a good dynamic decoupling between the primary control and the inner control, a filter is added on the active and reactive power measurement. Where $w_{c}$ is the cutting frequency [20].

$$
\begin{aligned}
p_{f} & =\frac{w_{c}}{w_{c}+s} p_{\text {mes }} \\
q_{f} & =\frac{w_{c}}{w_{c}+s} q_{\text {mes }}
\end{aligned}
$$

\section{Recall on Classical Tunning of Controllers}

As the states are transformed to the synchronous reference frame, they become DC signals under balanced sinusoidal grid and perfect synchronization. Under these conditions, PI controllers are sufficient to control the state variables without error in steady state. 




Figure 1. Grid-forming Control

\section{1) Current Controller Design:}

The control system requires a decoupled control of $i_{s d}$ and $i_{s q}$. However, the two axes are coupled due to the cross terms $L_{f} . i_{s q}$ and $L_{f} . i_{s d}$. These coupling terms are compensated by a feed-forward action, so that, the d-axis and q-axis components of currents can be controlled independently.

The current loop is constituted of three mains parts (Fig.2):

- A PI controller.

- An approximated transfer function of the PWM.

- A transfer function of the $R_{f}, L_{f}$ filter.

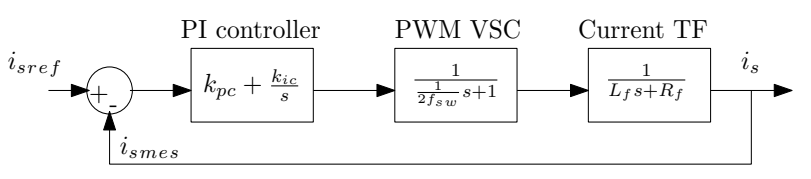

Figure 2. Current control loop

Were $k_{p}, k_{i}$ and $f_{s w}$ are respectively the PI controller gains,and the switching frequency. For the current controller design, the approximated PWM transfer function can be neglected if the current loop is at least 10 times slower than this latter, meaning that the response time of the current loop should be chosen higher than:

$$
T_{r c} \geq \frac{30}{2 f_{s w}}
$$

Where $T_{r c}$ is the current loop response time.

\section{2) Voltage Controller Design:}

Similar to what is done for the current loop, the voltage loop is constituted of three mains parts (Fig.3) :

- A PI controller.

- An approximated transfer function of the current loop.
- A transfer function of the capacitor.

In this case, if the response time of the voltage loop is 10 times higher than the current loop response time, the effect of the current transfer function may be neglected in the calculation of the PI controller parameters.

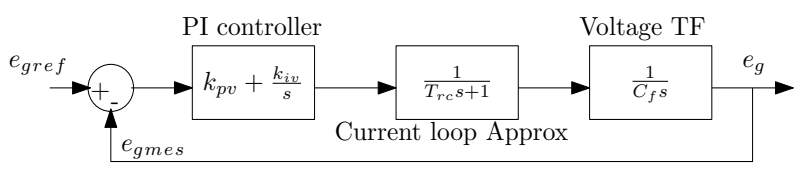

Figure 3. Voltage control loop

All the simulation parameters are given in Table I. The response time of the current and voltage loops are respectively set to $5 \mathrm{~ms}$ and $50 \mathrm{~ms}$ with damping ratio of $\zeta=0.7$.

TABLE I

SYSTEM PARAMETERS

\begin{tabular}{|c|c||c|c|}
\hline Parameter & Value & Parameter & Value \\
\hline \hline Real power $P_{n}$ & $1 \mathrm{GW}$ & $m_{p}$ & $0.02 \mathrm{pu}$ \\
\hline Power factor $\cos \phi$ & 0.95 & $n_{q}$ & $0.001 \mathrm{pu}$ \\
\hline Rated frequency $f_{n}$ & $50 \mathrm{~Hz}$ & $E_{\text {set }}$ & $1 \mathrm{pu}$ \\
\hline Switching frequency $f_{s w}$ & $5 \mathrm{kHz}$ & $P_{r e f}$ & $0.1 \mathrm{pu}$ \\
\hline DC voltage $U_{d c}$ & $640 \mathrm{kV}$ & $Q_{r e f}$ & $0 \mathrm{pu}$ \\
\hline AC Line-Line voltage $U_{a c}$ & $320 \mathrm{kV}$ & $w^{*}$ & $1 \mathrm{pu}$ \\
\hline Filter resistance $R_{f}$ & $0.005 \mathrm{pu}$ & $w_{c}$ & $31.4 \mathrm{rad} / \mathrm{s}$ \\
\hline Filter inductance $L_{f}$ & $0.15 \mathrm{pu}$ & $k_{p c}$ & 0.4001 \\
\hline Transformer resistance $R_{c}$ & $0.005 \mathrm{pu}$ & $k_{p v}$ & 0.017 \\
\hline Filter capacitance $C_{f}$ & $0.066 \mathrm{pu}$ & $k_{i c}$ & 171.88 \\
\hline Transformer inductance $L_{c}$ & $0.15 \mathrm{pu}$ & $k_{i v}$ & 0.75 \\
\hline
\end{tabular}




\section{Limitation of the classical controllers tuning}

Given the controller parameters calculated previously, some time domain simulations are presented for two different cases:

- K1 OFF: Standalone mode

- K1 ON: Grid connected mode

1) Stand-alone mode: The load is assumed purely resistive. Two events are applied to the system in order to check its behavior and stability :

- Load variation from $P_{\text {load }}=0.1 \mathrm{pu}$ to $P_{\text {load }}=0.4 \mathrm{pu}$.

- Variation of 0.1 on $\mathrm{AC}$ voltage step of $E_{\text {set }}=0.1 \mathrm{pu}$.

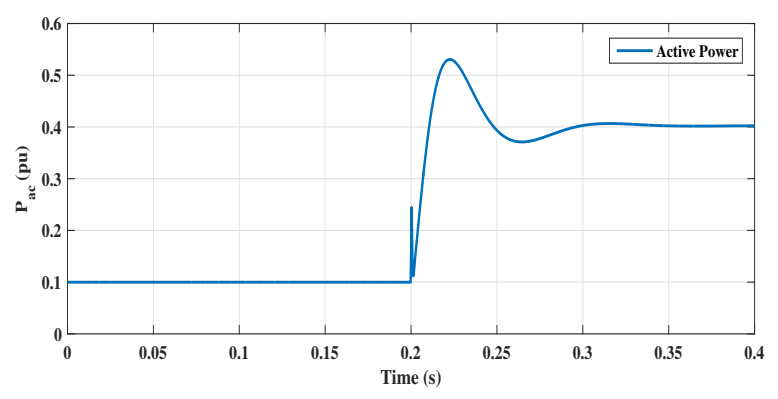

Figure 4. Active power dynamics over load variation

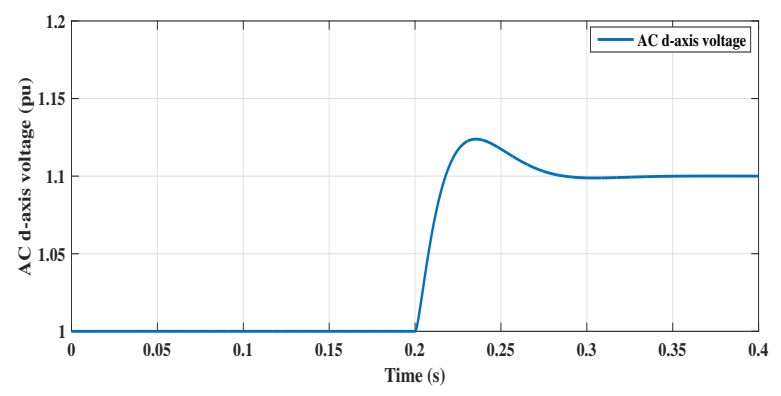

Figure 5. Effect of step on d-axis AC Voltage

The dynamic response of the $\mathrm{AC}$ voltage and the power correspond to what was expected.

2) Grid-connected mode: The grid is assumed very stiff $(\mathrm{SCR}=20)$. The control developed in stand-alone remains unchanged but the system is now largely modified.

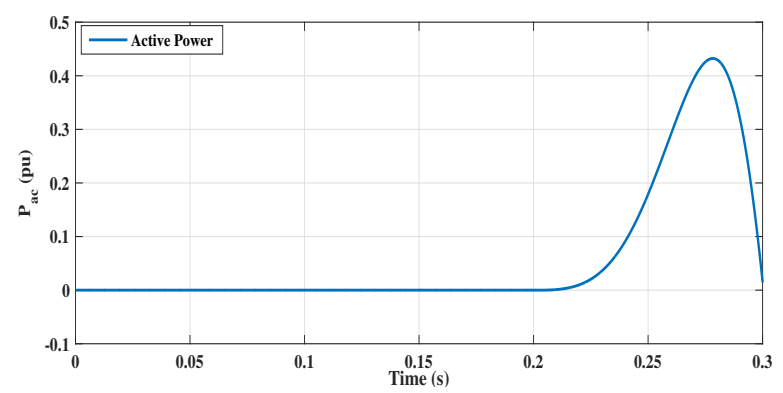

Figure 6. Active power dynamics over operating point change
Following an operating point change $\left(P_{0}=0 p u\right.$ to $P_{0}=$ $0.4 p u$ ), Figure 6 highlights that the power reference is not controlled any more since the system is unstable. Small-signal analysis and participation factors are used in the next section in order to analyze the dynamics of the system and find the origin of the instability.

\section{SMALL-SIGNAL ANALYSIS FOR GRID-FORMING CONVERTER}

To analyze the problem previously described, a mathematical formulation is developed by combining the system dynamics and the control equations. These latter can be linearized around an operating point using small-signal analysis:

$$
\begin{gathered}
\Delta \dot{X}=\left[A_{l}\right] \Delta X+\left[B_{l}\right] \Delta U \\
{[\Delta X]^{T}=\left[\begin{array}{llllllll}
\Delta \theta & \Delta P & \Delta Q & \Delta C_{v d q} & \Delta C_{c d q} & \Delta i_{s d q} & \Delta e_{g d q} & \Delta i_{g d q}
\end{array}\right]}
\end{gathered}
$$

$\Delta X$ represents all the state variables of the system when the converter is connected to the grid. To the 6 variables of the LCL filter, 7 others has been added :

- Four intermediate states of PI controllers of the current and voltage loop.

- Two outputs of the filter on P and Q.

- The angle $\theta_{\text {ref }}$ generated by the droop control on P.

$\Delta U$ represents the system inputs $\left(E_{\text {set }} w * P_{\text {ref }} \Delta v_{g d}\right.$ $\left.\Delta v_{g q}\right) . B_{l}$ is the input matrix and $A_{l}$ represents the state matrix which allows to analyze the stability.

In this calculation, the compensation of capacitor voltage $\left(e_{g d}\right.$, $\left.e_{g q}\right)$ and current $\left(i_{g d}, i_{g q}\right)$ are maintained $(H 1=1, H 2=1$ (Fig.1)).

TABLE II

SYSTEM EIGENVALUES

\begin{tabular}{|l|l|}
\hline \hline$\lambda_{1-2}=-419.35 \pm \mathrm{j} 3505.5$ & $\lambda_{3-4}=-417.08 \pm \mathrm{j} 2889.8$ \\
\hline$\lambda_{5-6}=30.522 \pm \mathrm{j} 30.24$ & $\lambda_{7-8}=-5.64 \pm \mathrm{j} 30.27$ \\
\hline$\lambda_{9-10}=-19.53 \pm \mathrm{j} 22.62$ & $\lambda_{11-12}=-35.224 \pm \mathrm{j} 9.39$ \\
\hline$\lambda_{13}=-31.52 \pm \mathrm{j} 0$ & \\
\hline
\end{tabular}

It can be noticed on table II that $\lambda_{5-6}$ have a positive real part which does not respect the stability condition as verified on the time domain simulation (Fig.6).

To define the link between the unstable modes and system states, the participation factors [22] $P_{\text {Factor }}$ are used to determine how much the $i^{t h}$ state variable participates in the $j^{\text {th }}$ mode.

The participation factor for $\lambda_{5-6}$ is presented on Fig.7. It reveals an important link between the unstable modes and especially the currents $i_{s d}, i_{s q}$.

The most common solutions [15]-[21] consist to act on the feed-forward disturbances rejection in the inner loops, e.g., in [19] H2 is set to zero, and in [18] H1 is set to zero. These solutions are considered as the references solutions which will be compared to the one developed in this paper. 




Figure 7. State participation in $\lambda_{5-6}$

\section{PROPOSED TUNING CONTROL ALGORITHM}

The proposed method assesses the gains of the controller which gives the best placement of the poles of the system calculated on the $13^{\text {rd }}$ order system meaning that the converter is grid-connected mode. Thereafter, it is verified that it is also valid for the isolated mode.

\section{A. Methodology}

The determination of controllers parameters is done following three steps:

1- At first, the eigenvalues are calculated for a large range of the four controllers parameters.

2- Two constraints are imposed on the system poles:

$$
\begin{array}{r}
\Re \lambda_{i}\left(A_{l}\right)<0 \\
\Re \lambda_{i}\left(A_{l}\right)>w_{0}
\end{array}
$$

Where $w_{0}=-800 \mathrm{rad} / \mathrm{s}$.

The choice of $w_{0}$ is linked to the limited bandwidth of converters which are connected to the transmission grids. When the poles respect these two constraints, the set of the 4 parameters is stored.

3- The third step consists in calculating the damping of each pole for each solution and comparing them.

The damping ratio is calculated for different poles for all the solutions which respect the constraints. For each solution, the smaller damping is isolated $\left(\zeta_{i_{m i n}}\right)$. All the $\left(\zeta_{i_{m i n}}\right)$ are compared. Finally, the solution which is chosen is the one which gives the maximum damping in all the $\left(\zeta_{i_{m i n}}\right)$. This guarantee to have the optimal dynamic behavior among all the possible solutions with the chosen set of parameters for the 2 controllers.

TABLE III

CONTROLLERS PARAMETERS

\begin{tabular}{|c||c|}
\hline Parameter & Proposed algorithm \\
\hline \hline Voltage controller gain $k_{p v}$ & $0.52 \mathrm{pu}$ \\
\hline Voltage controller integral gain $k_{i v}$ & $1.16 \mathrm{pu}$ \\
\hline Current controller gain $k_{p c}$ & $0.73 \mathrm{pu}$ \\
\hline Current controller integral gain $k_{i c}$ & $1.19 \mathrm{pu}$ \\
\hline
\end{tabular}

It can be noted from Table III that the obtained controllers parameters are very different from those calculated using the classical tuning method (Table I). The two parameters that had a lot of impact on pole placement are especially the current
TABLE IV

SYSTEM EIGENVALUES

\begin{tabular}{|l|l|}
\hline \hline$\lambda_{1-2}=-781.07 \pm \mathrm{j} 3534$ & $\lambda_{3-4}=-754.64 \pm \mathrm{j} 3011.8$ \\
\hline$\lambda_{5-6}=-36.65 \pm \mathrm{j} 97.433$ & $\lambda_{7-8}=-12.98 \pm \mathrm{j} 29.49$ \\
\hline$\lambda_{9}=-31.57$ & $\lambda_{10}=-2.3468$ \\
\hline$\lambda_{11}=-2.1055$ & $\lambda_{12}=-1.5605$ \\
\hline$\lambda_{13}=-1.6813$ & \\
\hline
\end{tabular}

controller integral gain $K_{i c}$ and voltage controller proportional gain $K_{p v}$. Using these new controllers parameters, The table IV shows the resultant eigenvalues of the system. The minimum damping is associated to $\lambda_{1-2}$, its value is 0.21 . Since the system is non linear, the choice of the operating point is important. The gains have been calculated for the nominal operating point $(\mathrm{P0}=1 \mathrm{pu})$.

\section{B. Comparison with other methods}

A time domain simulation is presented in order to validate the parameters derived from the proposed algorithm and compare with the two other solutions proposed in the literature: The simulation is done on MATLAB/SimpowerSystem using the system parameters in Table I.

- In [19], the proposed solution is to set H2 to zero keeping the classical tuning obtained in standalone mode. It is shown that it improves the stability. However the dynamics of the system is not controlled anymore.

- In [18], H1 is set to zero and the gain of the controller are calculated to get the best behavior as possible but the damping is not good enough. .

In order to excite the modes linked to the inner loops, an event is applied on $\mathrm{AC}$ voltage $E_{\text {set }}=1.1 \mathrm{pu}$ at $\mathrm{t}=2 \mathrm{~s}$.


Figure 8. AC d-axis voltage and VSC output current

On Figure 8, the results show clearly the improvement brought by the proposed method. It illustrates that the proposed algorithm is effective in ensuring the stability and improving the dynamic performance of the system compared to what have been achieved using the two other approaches. 


\section{Robustness of the Grid-forming Voltage Source Converter}

As mentioned in the introduction, the robustness of the proposed control is a major property to be tested since the converter is subjected to various situations due to the modification of the grid topology. Four studies are realized without changing any parameters of controllers presented in table III:

- Influence of the operating point.

- Variation of Short Circuit Ratio.

- Standalone mode.

- Multi-converters grid topology.

\section{1) Influence of operating point:}

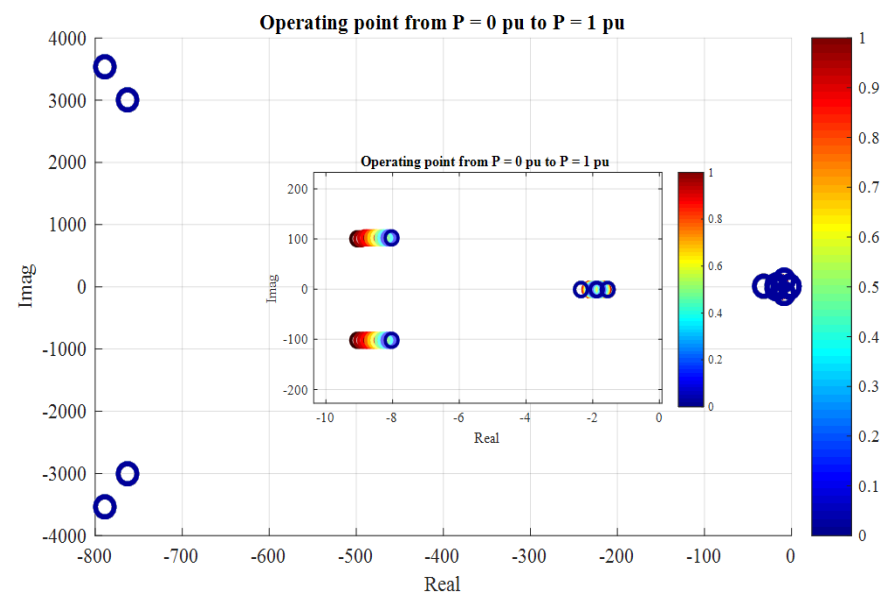

Figure 9. Modes evolution in case of operating point change

Figure 9 analyses the evolution of poles in respect with the active power operating point. It highlights that an operating point modification has a small impact on the system stability.

\section{2) Variation of Short circuit Ratio:}

The evolution of poles is now analyzed in respect with the Short Circuit Ratio from 20, very strong grid, to 1.2 which is a very weak grid. The poles have been calculated for the nominal operating point: $\mathrm{P} 0=1 \mathrm{pu}$.


Figure 10. Modes evolution in case of SCR variation.Left:All system poles. Right:Zoom on poles close to zero
Figure 10 highlights that the variation of the Short Circuit Ratio has a stronger impact particularly on the mode related to the angle. However the system remains stable for a very wide interval.

\section{3) Standalone mode:}

In figure 11, the same tests as in Section II-D-1 are achieved: a load variation from $P_{\text {load }}=0.1$ pu to $P_{\text {load }}=1$ pu and $\mathrm{AC}$ voltage variation $E_{\text {set }}=1.1 \mathrm{pu}$ at $\mathrm{t}=0.2 \mathrm{~s}$.
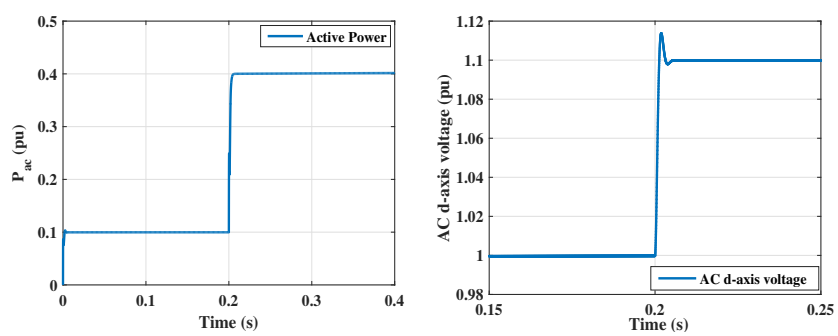

Figure 11. Left:Effect of the load variation on the active power. Right:Effect of step on d-axis AC Voltage

These results confirm that the control strategy, designed for a grid-connected mode, is also able to operate in stand-alone mode with a very good stability margin.

\section{4) Multi-converter grid topology:}

An extension of the stand alone configuration is the a connection of two grid forming converters through a transmission line. For this test, three events are realized:

- At $\mathrm{t}=1 \mathrm{~s}$ a load variation is applied (from $\mathrm{P}=0.2$ pu to $\mathrm{P}=$ $0.6 \mathrm{pu})$.

- At $\mathrm{t}=3 \mathrm{~s}$ a power step is applied on VSC2 $(\mathrm{P} 0=0.4 \mathrm{pu})$.

- At $\mathrm{t}=5 \mathrm{~s}$, a line tripping is applied.

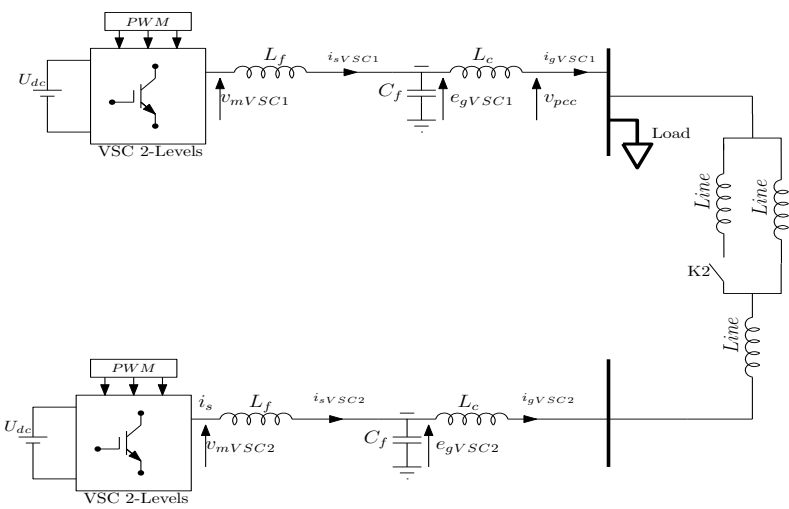

Figure 12. Multi-converter topology

Both converters are of identical rated power. The parameters of the controllers used are those in table II.

From Fig.13, it can be concluded that this control strategy is robust against events that may occur in a transmission grid (line opening, load variation, etc.). 


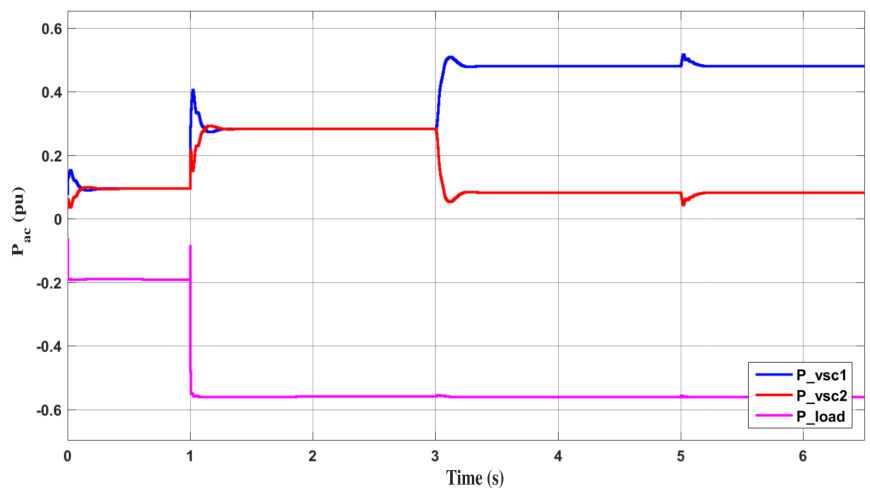

Figure 13. Multi-converters topology

\section{CONCLUSION}

This paper presents an algorithm to determine the controllers parameters which consists in giving the pole of the system the best damping ratio using the linearized small signals model. The principle of the algorithm consists in varying the controllers parameters at each iteration by imposing a set of stability, dynamics and damping constraints on the system poles. This algorithm is applied to a gridforming voltage source converter with a cascaded multi-loop controller. The results obtained show that the proposed method provides a good dynamic behavior comparing to what has been achieved with the controllers tuning in the literature. More over, these set of parameters calculated for a given operating point and topology reveals a very good robustness in various topologies. The following works will be focused on the behavior in case of short circuit, which is another challenge to tackle for the grid forming converters. In addition, the interest in the Modular Multilevel Converters topology will increase, given its ability to generate an output AC voltage close to a sinusoid, therefore, no need to add an LCL filter which will greatly reduce dynamic interactions.

\section{ACKNOWLEDGMENT}

This project has received funding from the European Union's Horizon 2020 research and innovation program under grant agreement No 691800.

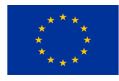

\section{DISCLAIMER}

This paper reflects only the author's views and the European Commission is not responsible for any use that may be made of the information it contains.

\section{REFERENCES}

[1] P. Rault, "Introduction au contrôle commande des réseaux HVDC Multiterminaux", Ecole Centrale de Lille,Ph.D dissertion, 2013.

[2] R. Ottersten and J. Svensson, "Vector current controlled voltage source converter-deadbeat control and saturation strategies," in IEEE Transactions on Power Electronics, vol. 17, no. 2, pp. 279-285, Mar 2002.
[3] J. Svensson and M. Lindgren, "Vector current controlled grid connected voltage source converter-influence of nonlinearities on the performance," PESC 98 Record. 29th Annual IEEE Power Electronics Specialists Conference (Cat. No.98CH36196), Fukuoka, 1998, pp. 531-537 vol.1.

[4] L. Zhang, L. Harnefors and H. P. Nee, "Power-Synchronization Control of Grid-Connected Voltage-Source Converters," in IEEE Transactions on Power Systems, vol. 25, no. 2, pp. 809-820, May 2010.

[5] Allal M. Bouzid, Josep M. Guerrero, Ahmed Cheriti, Mohamed Bouhamida, Pierre Sicard, Mustapha Benghanem, A survey on control of electric power distributed generation systems for microgrid applications, In Renewable and Sustainable Energy Reviews, Volume 44, 2015, Pages 751-766, ISSN 1364-0321,

[6] P. Zhou, X. Yuan, J. Hu and Y. Huang, "Stability of DC-link voltage as affected by phase locked loop in VSC when attached to weak grid," 2014 IEEE PES General Meeting - Conference \& Exposition, National Harbor, MD, 2014, pp. 1-5.

[7] J. Z. Zhou, H. Ding, S. Fan, Y. Zhang and A. M. Gole, 'Impact of ShortCircuit Ratio and Phase-Locked-Loop Parameters on the Small-Signal Behavior of a VSC-HVDC Converter," in IEEE Transactions on Power Delivery, vol. 29, no. 5, pp. 2287-2296, Oct. 2014.

[8] Debry, Marie-Sophie, Denis, Guillaume, Prevost, Thibault, Xavier, Florent, Menze, Andreas. (2016). Maximizing the penetration of inverterbased generation on large transmission systems: the MIGRATE project. Zenodo.

[9] J. Rocabert, A. Luna, F. Blaabjerg and P. Rodríguez, "Control of Power Converters in AC Microgrids," in IEEE Transactions on Power Electronics, vol. 27, no. 11, pp. 4734-4749, Nov. 2012.

[10] J. M. Guerrero, J. C. Vasquez, J. Matas, M. Castilla, and L. Garcia de Vicuna, "Control strategy for flexible microgrid based on parallel lineinteractive UPS systems," IEEE Trans. Ind. Electron., vol. 56, no. 3, pp. 726-736, 2009.

[11] W. Wu et al., "A Virtual Inertia Control Strategy for DC Microgrids Analogized With Virtual Synchronous Machines," in IEEE Transactions on Industrial Electronics, vol. 64, no. 7, pp. 6005-6016, July 2017.

[12] N. Pogaku, M. Prodanovic and T. C. Green, "Modeling, Analysis and Testing of Autonomous Operation of an Inverter-Based Microgrid," in IEEE Transactions on Power Electronics, vol. 22, no. 2, pp. 613-625, March 2007.

[13] F. Katiraei, R. Iravani, N. Hatziargyriou and A. Dimeas, "Microgrids management," in IEEE Power and Energy Magazine, vol. 6, no. 3, pp. 54-65, May-June 2008.

[14] G. Denis, T. Prevost, P. Panciatici, X. Kestelyn, F. Colas and X. Guillaud, "Review on potential strategies for transmission grid operations based on power electronics interfaced voltage sources," 2015 IEEE Power \& Energy Society General Meeting, Denver, CO, 2015, pp. 1-5.

[15] F. Salha, "Microréseaux îlotables: étude et coordination des protections des générateurs et du réseau," Phd Thesis, Ecole Centrale de Lille, 2010.

[16] J. M. Guerrero, J. C. Vásquez, J. Matas, M. Castilla, and L. García de Vicuna, "Control strategy for flexible microgrid based on parallel lineinteractive UPS systems," IEEE Trans. Ind. Electron., vol. 56, no. 3, pp. 726-736, 2009

[17] Y. W. Li and C.-N. Kao, "An accurate power control strategy for powerelectronics-interfaced distributed generation units operating in a lowvoltage multibus microgrid," IEEE Trans. Power Electron., vol. 24, no. 12, pp. 2977-2988, 2009.

[18] S. D'Arco, J. A. Suul, and O. Fosso, "Automatic Tuning of Cascaded Controllers for Power Converters using Eigenvalue Parametric Sensitivities," IEEE Trans. Ind. Appl., vol. 9994, no. c, pp. 1-1, 2014.

[19] G. Denis, T. Prevost, P. Panciatici, X. Kestelyn, F. Colas and X. Guillaud, "Improving robustness against grid stiffness, with internal control of an AC voltage-controlled VSC.," 2016 IEEE Power and Energy Society General Meeting (PESGM), Boston, MA, 2016, pp. 1-5.

[20] Y. A. R. I. Mohamed and E. F. El-Saadany, "Adaptive Decentralized Droop Controller to Preserve Power Sharing Stability of Paralleled Inverters in Distributed Generation Microgrids," in IEEE Transactions on Power Electronics, vol. 23, no. 6, pp. 2806-2816, Nov. 2008.

[21] E. A. A. Coelho, P. C. Cortizo, and P. F. D. Garcia, "Small-signal stability for parallel-connected inverters in stand-alone AC supply systems," IEEE Trans. Ind. Appl., vol. 38, no. 2, pp. 533-542, 2002.

[22] S. Danielsen, O. B. Fosso, and T. Toftevaag, "Use of participation factors and parameter sensitivities in the study and improvement of low frequency stability between electric rail vehicle and power supply," in Proc. 13th EPE, Barcelona, Spain, Sep. 8-10, 2009, pp. 1-10.

[23] www.h2020-migrate.eu 